\title{
On diagnosing Soft Tissue Sarcomas; an editorial
}

\author{
Kripouri Panagiota $^{1 *}$ and Filippou Dimitrios ${ }^{2}$ \\ ${ }^{1}$ Postgraduate Student, Department of Anatomy and Surgical Anatomy, Medical School, National and Kapodistrian University of Athens, Athens, Greece \\ ${ }^{2}$ Chief General Surgeon, Department of Anatomy and Surgical Anatomy, Medical School, National and Kapodistrian University of Athens, Athens, Greece
}

Soft tissue sarcomas (STS) are tumors arising from mesenchymal tissue which consist of muscle, fat, blood vessels, fibrous and other supporting tissue. They are also known as connective tissue cancers. These tumors include a vast variety of histological types that are often distinctive in incidence patterns and possible clinical outcome. [1] STS comprise $1-5 \%$ of all malignancies in adults [2] with an estimated 12,390 new cases in 2017 in the USA [3]. However, the past two decades have been a significant improvement in prognosis. The incidence of soft tissue sarcomas is increasing with the age although they do occur in younger patients [2].

Two thirds of sarcomas are found in the extremities and often present as a lump in patients who are generally in good health and physical condition, with no pain or functional alterations [4]. Earlier diagnosis is linked to better outcomes. The size of the tumor can be large, mean size about $9.87 \mathrm{~cm}$ [5]. Due to STS being rare it has been suggested that they should be treated at a specialist center [6]. Soft tissue sarcomas remain a very difficult group of malignant tumors to treat because of their diversity in terms of grade, histology, metastatic potential and anatomical locations. Optimal treatment requires preoperative staging, including magnetic resonance imaging of the tumor, chest CT (x-ray is acceptable in certain cases), and biopsy (mostly core needle), while brain imaging may be considered in tumors with specific attributes according to UK guidelines [7].

American Joint Committee on Cancer (AJCC) TNM staging system is a commonly used staging system although it has been criticized [8]. For correct diagnosis of the many types of soft tissue sarcomas (more than 50) immunohistochemistry is recommended and fragments for further testing (blood and samples for cytogenetics) in bio-banks (consent needed) according to the Spanish group for research in sarcomas. Fine needle aspiration is seldom adequate to accurately define a tumor but is useful to diagnose metastases or recurrence according to the same group [9]. Image-guided biopsy has been recommended and surgical excisional biopsy is only chosen under specific circumstances [10]. Another paper recommends incisional biopsy with cautious hemostasis, [11] but according to the UK guidelines core needle biopsy with several cores taken is preferred. UK guidelines suggest that incisional biopsies may still be useful in certain cases [7] The European Sarcoma Network Working Group agrees; standard approach is core needle biopsy; open biopsy should be contacted in selected cases and FNA should only be performed by experienced centers [12].

We believe that undergraduate medical students, general doctors and surgery residents should all be well aware of this type of cancer.

Copyright: (C2018 Panagiota K. This is an open-access article distributed under the terms of the Creative Commons Attribution License, which permits unrestricted use, distribution, and reproduction in any medium, provided the original author and source are credited.
According to the UK guidelines in cases of retroperitoneal or intraabdominal mass with imaging features of soft tissue sarcoma should be referred to specialists immediately. [7] However, less experienced surgeons may be asked to perform biopsies of masses on the extremities and adherence to the recent guidelines for biopsies in suspected sarcomas is crucial. Earlier and correct diagnosis of sarcomas leads to a more effective management and makes an enormous difference in patient's quality of life and prognosis.

\section{Conflict of interest}

Authors declare no conflict of interest.

\section{References}

1. Park JW, Kim HS, Lee C, Yoo HJ, Yun J Y, et al. (2017) Preoperative Factors Associated with Infiltrative Histologic Growth Patterns in Extremity Soft Tissue Sarcoma. Sarcoma: 5419394. [Crossref]

2. Ferrari A, Sultan I, Huang TT, Rodriguez-Galindo C, Shehadeh A et al. (2011) Soft Tissue Sarcoma Across the Age Spectrum: A Population-Based Study from the Surveillance Epidemiology and End Results Database. Pediatr blood cancer 57: $943-$ 949. [Crossref]

3. Siegel RL, Miller KD, Jemal A (2017) Cancer Statistics, 2017. CA Cancer J Clin 67 7-30. [Crossref]

4. Tukiainen E, Böhling T, Huuhtanen R (2003) Soft tissue sarcoma of the trunk and extremities. Scand J Surg 92: 257-263. [Crossref]

5. Smith G, Johnson G, Grimer R, Wilson S (2011) Trends in presentation of bone and soft tissue sarcomas over 25 years: little evidence of earlier diagnosis. Ann R Coll Surg Engl 93: 542-547. [Crossref]

6. Bhangu AA, Beard JAS, Grimer RJ (2004) Should Soft Tissue Sarcomas be Treated at a Specialist Centre? Sarcoma 8: 1-6. [Crossref]

7. Dangoor A, Seddon B, Gerrand C, Grimer R, Whelan J, et al. (2016) UK guidelines for the management of soft tissue sarcomas. Clin Sarcoma Res 6: 20. [Crossref]

8. Pasquali S, Gronchi A (2017) Neoadjuvant chemotherapy in soft tissue sarcomas: lates evidence and clinical implications. Ther Adv Med Oncol 9: 415-429. [Crossref]

9. Garcia del Muro X, de Alava E, Artigas V, Bague S, Braña A, et al. (2016) Clinical practice guidelines for the diagnosis and treatment of patients with soft tissue sarcoma by the Spanish group for research in sarcomas (GEIS). Cancer Chemother Pharmacol 77: 133-146. [Crossref]

10. Rochwerger A, Mattei JC (2017) Management of soft tissue tumors of the musculoskeletal system. Orthop Traumatol Surg Res: 104: S9-S17. [Crossref]

11. Czauderna P (2006) Role of surgery in the management of soft tissue tumors. Future Oncol 2: 667-673. [Crossref]

12. ESMO/European Sarcoma Network Working Group (2014) Soft tissue and viscera sarcomas: ESMO Clinical Practice Guidelines for diagnosis, treatment and follow-up. Ann Oncol 25: 102-112. [Crossref]

*Correspondence to: Panagiota Kripouri, MD, 80 Mesogion Avenue, GR-11527 Ampelokipi, Athens, Greece; E-mail: p_kripouri@yahoo.com

Received: March 29, 2018; Accepted: April 10, 2018; Published: April 12, 2018 